\title{
Research on the Current Situation of the Radioactive Material Safe Transport Management
}

\author{
Yingjun Huang ${ }^{a}$, Xudong Liao ${ }^{b}$, Bo Li ${ }^{c}$, Miao Lou ${ }^{d}$, Tao Chen ${ }^{e}$ \\ The North-West Institute of Nuclear Technology, Xi'an 710024, China

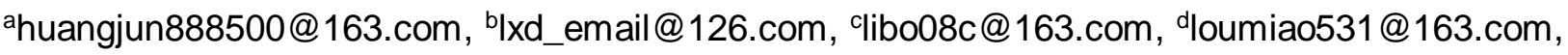 \\ eshuishou205@163.com
}

Keywords: IAEA, Radioactive Material, Safe Transport, Management Regulation.

\begin{abstract}
The domestic and overseas current situation of the radioactive material safe transport management was analyzed by researching the IAEA's radioactive material safe transport document and the development of the radioactive material safe transport management and the laws, regulations and national standard in China. A number of suggestions were thrown out to give references for the departments who want to formulate the regulation for the safe transport of radioactive material.
\end{abstract}

\section{Introduction}

The safe transport of radioactive material has been a major concern in the field of nuclear industry and nuclear technology at home and abroad. Once the radioactive material was leaked during transport, the environment will be polluted and the public will be harmed. Therefore, it is of great significance to strengthen the management of the safe transport of radioactive material. At present, the nuclear states and international organization involved in the management of dangerous goods all attached great importance to the transport and management of radioactive materials, and issued many laws, regulations and national standard. In this paper, the domestic and overseas current situation of the radioactive material transport management will be summarized by researching the radioactive material safe transport document published at home and abroad. It will provide some references for the departments who want to formulate the regulation for the safe transport of radioactive material.

\section{The International Radioactive Material Safe Transport Management}

At present, the most authoritative and important international organization to formulate the regulation for the radioactive material safe transport must be International Atomic Energy Agency (IAEA). It was an independent inter-governmental organization which was related with the United Nations and organized the science and technology cooperation in the atomic energy field among the member states.

The IAEA has formulated a lot of documents about the radioactive material safe transport management since its establishment in 1957, and the most central document must be the Regulation for the Safe Transport of Radioactive Material (IAEA RSTRM), IAEA SS No.6 [1]. It was formulated according to Fundamental Safety Principles, IAEA SS. No. SF-1 and International Basic Safety Standards for Protection against Ionizing Radiation and for the Safety of Radiation Sources, IAEA SS No.115 [2], in order to reduce the radiation hazards, thermal hazards and critical hazards to people and environment.

The IAEA RSTRM had provided a management framework for the transport of radioactive material from very low level to very high level, offered a range of technology and management safety requirements and control measures which had covered all aspects of safe transport. At present, it has been the safety basic of the radioactive material transport in the world [1]. It has been revised for many times since its issuing in 1961, and the current version was issued in 2012 which was classified into Special Safety Requirements with the number SSR-6 [3]. 
At present, the IAEA transport safety standard has been adopted by almost all the IAEA members, by February 2012 there were 153 members, and the international organizations related to the transport of radioactive materials. The IAEA RSTRM has become the basis and criterion for the international organizations and countries to formulate the regulations and safety standards. In 1963, Belgium has explicitly stipulated in the Royal Decree VII that the transport of radioactive materials in Belgium must comply with basic rules protecting the public and workers from ionizing radiation refer to the IAEA RSTRM [4]. Poland has issued the Atomic Energy Act refer to the IAEA RSTRM [5]. In order to strengthen the management of radioactive materials transport, American has developed the software RADTRAN and RISKIND based on the IAEA RSTRM, which could provide risk assessment for the radiation effects of radioactive materials on the group and individuals under normal transport and accident [6]. In 1999, the French nuclear safety administration (DSIN) announced to try the International Nuclear Event Scale (INES) of IAEA a year.

In order to help the relevant countries and international organizations implement the IAEA RSTRM, the IAEA formulated some guide rules in IEAE Safety Standard Series including Advisory Material for the IAEA Regulations for the Safe Transport of Radioactive Material, IAEA SS No.TS-G-1.1, Planning and Preparing for Emergency Response to Transport Accidents Involving Radioactive Material, IAEA SS No.TS-G-1.2, Radiation Protection Programmes for the Transport of Radioactive Material, IAEA SS No.TS-G-1.3, The Management System for the Safe transport of Radioactive Material, IAEA SS No.TS-G-1.4, Compliance Assurance for the Safe transport of Radioactive Material, IAEA SS No.TS-G-1.5, Schedules of Provisions of the IAEA Regulations for the Safe Transport of Radioactive Material (2009 Edition), IAEA SS No.TS-G-1.6, et al [7-12].

\section{The Radioactive Material Safe Transport Management in China}

The transport of radioactive material in China started in the late 1950s, and had few package each year. In the 1960s to 1980s, the transport of radioactive material package was managed by the industry management department without the approval process, and the products in the nuclear fuel cycle were transported as military goods [13]. In 1984, China joined the IAEA, and converted the IAEA RATRM to the national standard Regulation for the safe transport of radioactive material (GB 11806-89) which has been updated to GB 11806-2004 in 2004 [14]. It was the first comprehensive standard applicable to all transportation. After, the State Council Decree issued Regulation for the Safe Transport of Radioactive Material, State Council Decree [China] No.562 (2009), on September 14, 2009, which has put forward overall requirements for the management of the radioactive material safe transport [15]. The various ministries and commissions under the Central Government had issued a series of supporting department rules to regulate the transportation of radioactive materials. On October 7, 2010, Ministry of Communications issued Regulation for the Safe Transport of Radioactive Material, Ministry of Communications Decree [China] No.6 (2010) and modified it in 2016 as Ministry of Communications Decree [China] No.71 (2016), which has made detailed regulations on radioactive material transport, such as classification, department responsibilities, transportation qualification permits, special vehicle equipment management, et al [16]. On November 1, 2010, Ministry of Environmental Protection issued Management Measures for the Security Permission of Radioactive Material Transport, Ministry of Environmental Protection Decree [China] No.11 (2010), which has made detailed regulations on permits and regulations for the design and manufacture of the radioactive material transport container, approval and register of the radioactive material transport [17]. On March 14, 2016, Ministry of Environmental Protection issued Management Measures for the Security Supervision of Radioactive Material Transport, Ministry of Environmental Protection Decree [China] No.38 (2016) [18].

At the legal level, The people's Republic of China Law of prevention and control of radioactive contamination (2003 Edition) and The traffic safety law of the people's Republic of China (2011 Second Edition) have made the principled regulation for safe transport of radioactive material. 
At national standards level, GB 11806-2004 has identified with the IAEA RSTRM and stipulated fully detailed safety requirements for the transport of radioactive material. Quality assurance for packaging used in the transport of radioactive material, GB 15219-2009, has stipulated the quality assurance basic requirements of the packaging design, procurement, manufacture, loading and unloading, transportation, storage, inspection, testing, operation and so on [19]. Safe transport of radioactive material Leakage testing on packages, GB/T 17230-1998, has stipulated the processes and requirements of leakage testing on packages [20]. In addition, there are many laws, regulations, and national or industrial standards to comply with, such as Regulation for the transport of the people's Republic of China, State Council Decree [China] No.406 (2004), revised in 2016 [21]; The regulation of road transport of dangerous goods, Ministry of Communications Decree [China] No.2(2013) [22]; The regulation of automobile transportation of dangerous goods, JT 617-2004; The vehicle mark for road transportation dangerous goods, GB 13392-2005; Packing symbol of dangerous goods, GB 190-2009 and so on.

In accordance with the regulations of the country strictly, the domestic units has formulated some supporting transportation regulations of radioactive material transport. CGNPC Uranium Resources Co. Ltd. of China Guangdong Nuclear Power Group (CGN) has formulated Measures for the management of radioactive waste transportation, Regulation for the transfer of radioactive waste, The quality outline of radioactive waste transportation and so on. CNNC EVERCLEAN Environmental Technology Engineering Co. Ltd. of China National nuclear Corporation (CNNC) has formulated radiation protection outline, contingency plan, regulation for the safe transport of radioactive material and so on. At present, the transportation regulations formulated by the domestic units were mainly aimed at public transportation, and have no systematic management rules about internal short distance transportation.

\section{Conclusion}

Through the research and analysis of the domestic and overseas current situation of the radioactive material safe transport management, we can get the following conclusion:

(1) The IAEA RSTRM has been safety basic of almost all the IAEA members and the international organizations related to the transport of radioactive materials with strong guidance.

(2) The regulation for the safe transport of radioactive material in China was also based on the IAEA RSTRM. The government has issued a lot of laws, regulations and national standards to improve the management system.

(3) The transportation regulations formulated by the domestic units were mainly aimed at public transportation, and have no systematic management rules about internal short distance transportation.

\section{References}

[1] IAEA. Regulation for the Safe Transport of Radioactive Material (1985 Edition), IAEA Safety Standard No.6 [R]. Vienna: IAEA, 1985.

[2] IAEA. International Basic Safety Standards for Protection against Ionizing Radiation and for the Safety of Radiation Sources, IAEA Safety Standard No.115 [R]. Vienna: IAEA, 1996.

[3] IAEA. Regulation for the Safe Transport of Radioactive Material (2012 Edition), IAEA Safety Requirements No.SSR-6 [R]. Vienna: IAEA, 2012.

[4] Xuexin Wang. The Radioactive Material Transport in Belgium about Regulation [J]. Radiation Protection Bulletin, 1998, 18(6): 56-58.

[5] Xuexin Wang. The Regulation of Radioactive Material Transport in Poland [J]. Radiation Protection Bulletin, 1999, 19(5): 43-46.

[6] Shuyong Li. Safety Study Status Abroad for Radioactive Material Transportation [J], Guangdong Chemical Industry, 2009, 36(3): 85-87 
[7] IAEA. Advisory Material for the IAEA Regulations for the Safe Transport of Radioactive Material, IAEA Safety Standard No.TS-G-1.1 [R]. Vienna: IAEA, 2014.

[8] IAEA. Planning and Preparing for Emergency Response to Transport Accidents Involving Radioactive Material, IAEA Safety Standard No.TS-G-1.2 [R]. Vienna: IAEA, 2002.

[9] IAEA. Radiation Protection Programmes for the Transport of Radioactive Material, IAEA Safety Standard No.TS-G-1.3 [R]. Vienna: IAEA, 2007.

[10] IAEA. The Management System for the Safe transport of Radioactive Material, IAEA Safety Standard No.TS-G-1.4 [R]. Vienna: IAEA, 2008.

[11] IAEA. Compliance Assurance for the Safe transport of Radioactive Material, IAEA Safety Standard No.TS-G-1.5 [R]. Vienna: IAEA, 2009.

[12] IAEA. Schedules of Provisions of the IAEA Regulations for the Safe Transport of Radioactive Material (2009 Edition), IAEA Safety Standard No.TS-G-1.6 (Rev.1) [R]. Vienna: IAEA, 2014.

[13] Xinhua Liu, Hao Wu, Fangfang Cao, et al. The Practical Guide of Regulation for the safe transport of radioactive material (GB 11806) [M]. Beijing: Science Press.2015

[14] GB 11806-89 Regulation for the safe transport of radioactive material [S].

[15] China. Regulation for the Safe Transport of Radioactive Material [R]. State Council Decree [China] No.562, 2004.

[16] China. Regulation for the Safe Transport of Radioactive Material [R]. Ministry of Communications Decree [China] No.6, 2010.

[17] China. Management Measures for the Security Permission of Radioactive Material Transport [R]. Ministry of Environmental Protection Decree [China] No.11, 2010.

[18] China. Management Measures for the Security Supervision of Radioactive Material Transport [R]. Ministry of Environmental Protection Decree [China] No.38, 2016.

[19] GB 15219-2009 Quality assurance for packaging used in the transport of radioactive material [S].

[20] GB/T 17230-1998 Safe transport of radioactive material Leakage testing on packages [S].

[21] China. Regulation for the transport of the People's Republic of China [R]. State Council Decree [China] No.406, 2004.

[22] China. The regulation of road transport of dangerous goods, Ministry of Communications Decree [China] No.2 (2013). 